\title{
EPICUTICULAR COMPONENTS FROM PSEUDOGNAPHALIUM ROBUSTUM (ASTERACEAE): CHEMOSYSTEMATIC CONSIDERATIONS
}

\author{
ALEJANDRO URZÚA, LEONORA MENDOZA \\ Universidad de Santiago de Chile, Facultad de Química y Biología, Departamento de Ciencias del Ambiente, \\ Laboratorio de Química Ecológica, Casilla 40, Correo-33, Santiago, Chile. \\ (Received: 6 September 2007 - Accepted: 7 December 2007)
}

\begin{abstract}
Surface compounds were obtained by a methylene chloride extraction of fresh aerial parts of Pseudognaphalium robustum. The methylene chloride extract was fractionated by CC and the fractions were analyzed by GC-MS. Since flavonoids and terpenes are present only in small amounts in the epicuticular exudate of $P$. robustum, $80 \%$ of the surface compounds actually correspond to a complex mixture of saturated fatty acid esters, unsaturated fatty acid esters, alcohols, aldehydes, fatty acids, alkenes, triglycerides and monoglycerides. A minor hydrocarbon fraction of n-alkanes from C23 to C37 was also identified. On the contrary, in $P$. vira vira, $P$. cheiranthifolium, and $P$. heterotrichium, the epicuticular extracts contain from $70 \%$ to $80 \%$ of a mixture of diterpenoids and n-alkanes. These results show a remarkable distance between $P$. robustum and other species of the genus, which share the same ecosystem, when the whole pool of epicuticular compounds is taken into account. Also, these considerable differences in chemical composition are in agreement with authors that consider Pseudognaphalium as a heterogeneous taxonomic group.
\end{abstract}

Keywords: Pseudognaphalium robustum; Asteraceae; Methylene chloride extract, Epicuticular components; GC-MS; Saturated fatty acid esters; Unsaturated fatty acid esters; Epicuticular triglycerides; monoglycerides; Chemosystematic.

\section{INTRODUCTION}

The genus Pseudognaphalium (Asteraceae) is well represented in Chile by 14 species. All of them show a distinctive combination of non-glandular and glandular trichomes and the morphology of the latter varies according to species ${ }^{1,2}$. When present, the contribution of these specialised secretory structures to the surface chemistry of the plant is significant.

From the epicuticular extract of Pseudognaphalium robustum (initially reported as Gnaphalium), simple and acylated B-ring deoxyflavonoids had been isolated ${ }^{3-6}$. Monoterpenes and sesquiterpenes had been identified in the trichome secreted exudates ${ }^{7}$ and by headspace analysis ${ }^{8}$.

Flavonoids, mono- and sesquiterpenes are present only in small amounts in the epicuticular components of $P$. robustum, representing less than $8 \%$ of that fraction. In order to clarify the structure of the unidentified metabolites and establish any differences with other Chilean species of Pseudognaphalium with known epicuticular chemistry, a new study of $P$. robustum was undertaken.

Results shows that the chemical composition of the epicuticular components of $P$. robustum is considerable different to that of other Pseudognaphalium species that share with $P$. robustum the same ecosystem. These results are in agreement with authors that consider Pseudognaphalium as a heterogeneous taxonomic group.

\section{EXPERIMENTAL}

\section{Plant material}

Aerial parts of P. robustum (Phil.) A. Anderb. were collected during the flowering season, October 2003, between Zapallar and Papudo (V Región, Chile, $\left.32^{\circ} 30^{\prime} \mathrm{S}, 71^{\circ} 30^{\prime} \mathrm{W}\right)$. Voucher specimens were deposited in the Herbarium of the National Museum of Natural History, Santiago, Chile (SGO 133617-03).

Plant extraction and column chromatography separation of the extracts

Aerial parts of Pseudognaphalium robustum $(340 \mathrm{~g})$ were extracted by dipping the fresh plan material in $1.5 \mathrm{~L}$ of cold $\mathrm{CH}_{2} \mathrm{Cl}_{2}$ for $15-20 \mathrm{~s}$. The extraction was repeated twice to assure the total and selective extraction of the epicuticular components ${ }^{9,10}$. The $\mathrm{CH}_{2} \mathrm{Cl}_{2}$ extract $(1.2 \mathrm{~g}, 0.35 \%)$ was fractionated by $\mathrm{CC}$ (silica gel) using pentane $-\mathrm{CH}_{2} \mathrm{Cl}_{2}$ and $\mathrm{CH}_{2} \mathrm{Cl}_{2}-\mathrm{MeOH}$ step gradients. Fractions eluted with pentane $(47 \mathrm{mg})$, pentane- $\mathrm{CH}_{2} \mathrm{Cl}_{2}(9: 1)$, $(47 \mathrm{mg})$, pentane- $\mathrm{CH}_{2} \mathrm{Cl}_{2}(7: 3),(440 \mathrm{mg})$, and pentane- $\mathrm{CH}_{2} \mathrm{Cl}_{2}(6: 4),(440 \mathrm{mg})$ were submitted to extensive GC-MS analysis.

GC-MS analysis of the $\mathrm{CH}_{2} \mathrm{Cl}_{2}$ extract

The fractions were analysed in triplicate by two GLC/EI/QI-MS analysis in FISONS MD-800 equipment with a HP Ultra-2 capillary column $(12 \mathrm{~m}$ x $0.20 \mathrm{~mm})$ in one case and a HP Ultra-2 capillary column $(25 \mathrm{~m} \times 0.20 \mathrm{~mm})$ in the other. In the former analysis, injector temperature was $270^{\circ} \mathrm{C}$ and column temperature was programmed starting at $80^{\circ} \mathrm{C}$, for $2 \mathrm{~min}$, followed by a rise to $320^{\circ} \mathrm{C}$ at $20^{\circ} \mathrm{C} \mathrm{min}^{-1}$. Helium was the carrier gas at $7 \mathrm{lb}$ psi. In the later analysis, injector temperature was $270^{\circ} \mathrm{C}$ and column temperature was programmed starting at $40^{\circ} \mathrm{C}$, for $3 \mathrm{~min}$, followed by a rise to $280^{\circ} \mathrm{C}$ at $15^{\circ} \mathrm{C} \mathrm{min}^{-1}$. Helium was the carrier gas at $0.7 \mathrm{kp} / \mathrm{cm}^{2}$.

Fractions were derivatised with $200 \mu \mathrm{L}$ of N-methyl-N-(trimethylsilyl) trifluoroacetamide (MSTFA) (Aldrich). The samples were heated at $70^{\circ}$ during $45 \mathrm{~min}$ and the excess of reagent was eliminated with a gentle stream of $\mathrm{N}_{2}$ to yield the TMS derivatives ${ }^{11}$.

\section{Yields of fractions and compounds}

Extract and compound yields were calculated in relation to fresh plant material. The percentage of different families and individual compounds was calculated from the peak areas of the chromatograms.
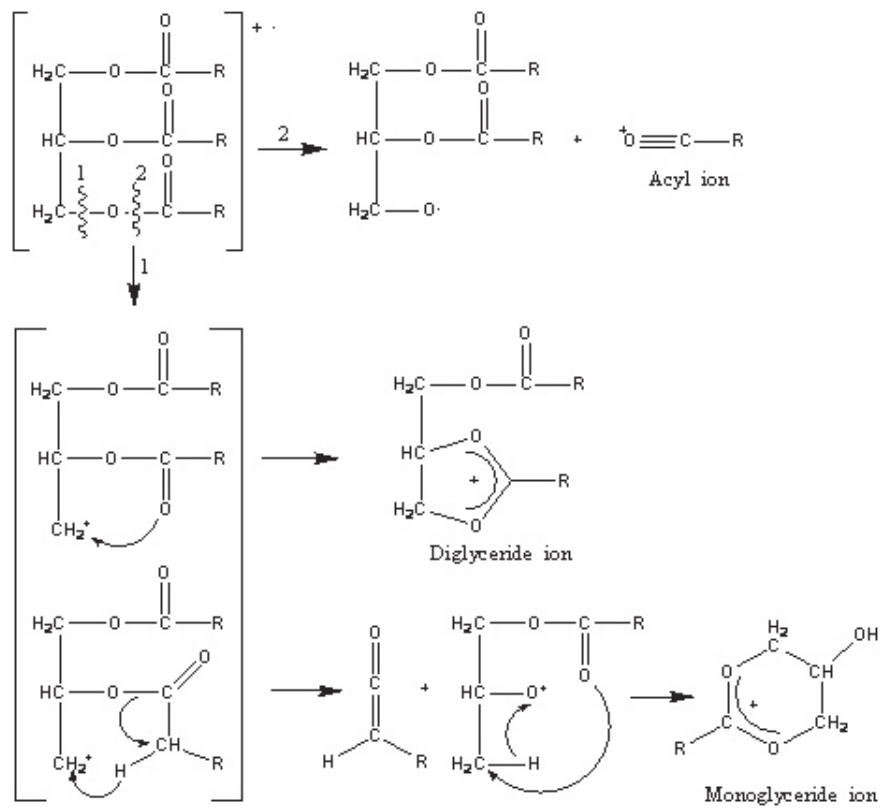

Figure $\mathbf{N}^{\mathbf{0}} \mathbf{1}$. Detailed mechanisms of ion fragmentation of triglycerides 


\section{RESULTS AND DISCUSSION}

\section{Identification of the epicuticular components}

n-Alkanes, n-alkenes, alcohols, fatty acid esters, aldehydes and fatty acids were identified by comparison of their retention time and MS spectra with standards (Sigma, Aldrich, Supelco) and of the mass spectra with data from the NIST library (1998) linked to the mass detector. Only correlation indexes greater than $98 \%$ were accepted.

The structures of triglycerides and monoglycerides (TMS derivatives) were obtained by interpretation of their mass spectra. In the case of triglycerides characteristics acyl, diglyceride and monoglyceride fragment ions were used $^{12}$.

The structure of monoglycerides was obtained by interpretation of the mass spectra of their TMS derivatives. In these compounds two ion fragments were considered: the acyl and the $\mathrm{M}+-103$ (base peak) formed by the heterolytic cleavage of the C1-C2 bond in 1-monoacylglycerols ${ }^{13}$. These were: $\mathrm{m} / \mathrm{z} 163$ and $\mathrm{m} / \mathrm{z} 315$ for 2, 3-dihydroxypropyl laurate, $\mathrm{m} / \mathrm{z} 187$ and $\mathrm{m} / \mathrm{z} 343$ for 2, 3dihydroxypropyl myristate, and m/z 211 and m/z 371 for 2, 3-dihydroxypropyl palmitate.

Finally identification was performed by comparison of their retention time and MS spectra with standards (Sigma).

\section{Chemical composition}

From the fractions eluted with pentane and pentane- $\mathrm{CH}_{2} \mathrm{Cl}_{2}(9: 1)$, the following not previously reported epicuticular compounds for $P$. robustum were identified: n-Alkanes (4\%): $\mathrm{C}_{23} \mathrm{H}_{48} ; \mathrm{C}_{24} \mathrm{H}_{50} ; \mathrm{C}_{25} \mathrm{H}_{52} ; \mathrm{C}_{26} \mathrm{H}_{54} ; \mathrm{C}_{27} \mathrm{H}$ ${ }_{56} ; \mathrm{C}_{28} \mathrm{H}_{58} ; \mathrm{C}_{29} \mathrm{H}_{60} ; \mathrm{C}_{30} \mathrm{H}_{62} ; \mathrm{C}_{31} \mathrm{H}_{64} ; \mathrm{C}_{32} \mathrm{H}_{66} \mathrm{C}_{33} \mathrm{H}_{68} ; \mathrm{C}_{34} \mathrm{H}_{70} ; \mathrm{C}_{35} \mathrm{H}_{72} ; \mathrm{C}_{36} \mathrm{H}$ ${ }_{74} ; \mathrm{C}_{37} \mathrm{H}_{76}$. n-Alkenes (0.3\%): 1-nonadecene. Alcohols (1\%): 1-tetradecanol; 1-hexadecanol. Saturated fatty acid esters (3\%): methyl dodecanoate (methyl laurate); methyl tetradecanoate (methyl myristate); methyl hexadecanoate (methyl palmitate); methyl heptadecanoate (methyl margarate); methyl docosonoate; methyl 5,9-dimethyldecanoate; methyl 9-oxononanoate; methyl 12-methyltridecanoate (methyl isomyristate); methyl 14-methylpentadecanoate; methyl 6-methylheptanoate; methyl 16-methyl heptadecanoate (methyl isoestearate); methyl 2-hexylcyclopropaneoctanoate. Unsaturated fatty acids esters (2.5\%): methyl (Z)-7-hexadecenoate (methyl palmitoleate); methyl (Z)-9-hexadecenoate; methyl (Z)-9-octadecenoate (methyl oleate); methyl acetylricinoleate; methyl (Z)-12 acetoxy-9-octadecenoate. Aldehydes $(0.5 \%)$ : nonanal; decanal.

From the fraction eluted with pentane- $\mathrm{CH}_{2} \mathrm{Cl}_{2}$ (7:3) the following not previously reported epicuticular compounds for $P$. robustum were identified: Triglycerides (40\%): glyceryl tridodecanoate (trilaurin); glyceryl trimyristate (trimyristin); glyceryl tripalmitate (tripalmitin); and several other triacylglycerol isomers, with combinations of lauric, myristic, palmitic and stearic acids, that were not identified.

From the fraction eluted with pentane- $\mathrm{CH}_{2} \mathrm{Cl}_{2}(6: 4)$ the following not previously reported epicuticular compounds for $P$. robustum were identified: Fatty acids (5\%): myristic acid; lauric acid. Monoglycerids (35\%): 2, 3dihydroxypropyl laurate; 2, 3-dihydroxypropyl myristate; 2, 3-dihydroxypropyl palmitate.

\section{Chemotaxonomic significance}

The composition profile of the hydrocarbon fraction of $P$. robustum is very much like that found in three other species of the genus: P. vira vira (Mol.) A. Anderb., P. cheiranthifolium (Lam.) Hilliard and Burtt. and P. heterotrichium (Phil.) A. Anderb. ${ }^{2}$. In contrast, the yields of these fractions remarkably differ among the four species. While $P$. robustum hydrocarbon yield corresponds to around $4 \%$ of the epicuticular components, in $P$. vira vira this percentage increases up to $50 \%$, and in $P$. cheiranthifolium and $P$. heterotrichium up to $35 \%$. These differences would not be ascribed to environmental conditions because the four species share the same eco-system. Another common composition profile among these four species is that of phenolic compounds, since their resinous exudates contain minute amounts of simple and acylated flavonoids lacking ring-B substitution ${ }^{3-6}$.

Considerable differences were found between $P$. robustum and the other Pseudognaphalium species concerning epicuticular terpenes. In relation to diterpenoids, ent-16-kauren-19-oic acid and ent-3- $\beta$-hydroxy-16- kauren19-oic acid have been isolated from $P$. heterotrichium, $P$. cheiranthifolium and P.vira vira. In addition, ent-9(11)-16-kauradien-19-oic acid and 13-episclareol have also been isolated from $P$. heterotrichium, and ent-3- $\alpha$ - hydroxy9(11),16-kauradien-19-oic acid and 13-epi-sclareol from P. cheiranthifolium.
In these three species, diterpenoid fractions account for around 30\% to $40 \%$ of the epicuticular compounds ${ }^{3,5}$. In contrast, only trace amounts of ent-16kauren-19-oic acid were found in P. robustum in a previous work ${ }^{3}$ and none in the samples analysed here.

Since flavonoids and terpenes are present only in small amounts in the epicuticular exudate of $P$. robustum, $91 \%$ of the surface compounds actually correspond to a complex mixture of hydrocarbons, alcohols, fatty acid esters, aldehydes, triglycerides and monoglycerides. On the contrary, in $P$. vira vira, $P$. cheiranthifolium and $P$. heterotrichium, the epicuticular extracts contain from $75 \%$ to $85 \%$ of a mixture of diterpenoids and n-alkanes ${ }^{2,3}$. These results show a remarkable distance between $P$. robustum and other species of the genus in the same eco-system, when the whole pool of epicuticular compounds is taken into account. In contrast, a correlation was not found between these chemical results and the glandular trichome morphology, frequency and distribution in each species ${ }^{14}$. In the four cases, glandular trichomes consist of bi-cellular glandular heads on top of multi-cellular columns that are extensions of the leaf epidermis. Those of $P$. robustum and $P$. heterotrichium are very similar, abundant and regularly distributed. In comparison to these, glandular trichomes in $P$. vira vira are scarce and distributed around and along leaf enervations. Finally, $P$. cheiranthifolium shows two types of glandular trichomes evenly distributed on both sides of leafs ${ }^{2}$.

Pseudognaphalium consisted originally of 10 species $^{15}$ and Anderberg remodelled it to comprise about $80^{2,16}$. Dillon and Sagástegui are reluctant to accept the present definition of this genus but, at the same time, they recognise that a potential reorganisation of Pseudognaphalium species cannot be proposed without the support of further studies on other related genus Gnaphalium, Achyrocline, and Stenocline ${ }^{17}$.

The considerable differences between the chemical composition of the cuticle of $P$. robustum found in this work and that of other species of the genus, which share the same ecosystem, are in agreement with Dillon and Sagástegui, who consider Pseudognaphalium as a heterogeneous taxonomic group and propose an extensive revision of the same ${ }^{17}$. In this context, the chemical data here reported may be supportive as part of relevant information in the genus revision.

\section{ACKNOWLEDGEMENT} 2003.

This work was supported by FONDECYT (Chile) grant $N^{\circ} 1030466-$

\section{REFERENCES}

1.- A. Anderberg, Opera Bot. 104, 1 (1991)

2.- L. Mendoza, Ph. D. Thesis, Facultad de Química y Biología, Universidad de Santiago de Chile, Chile (1997)

3.- L. Mendoza, A. Urzúa, Biochem. Syst. Ecol. 26, 469 (1998)

4.- A. Urzúa, P. Cuadra, Phytochemistry, 29, 1342 (1990)

5.- A. Urzúa, R. Torres, C. Bueno, L. Mendoza, Biochem. Syst. Ecol. 23, 459 (1995)

6.- A. Urzúa, L. Mendoza, E. Tojo, M. E. Rial, J. Nat. Prod. 62, 381 (1999)

7.- A. Urzúa, 2004. Biochem. Syst. Ecol. 32, 211 (2004)

8.- A. Urzúa, Bol. Soc. Chil. Ouím. 47, 99 (2002)

9.- A. Urzúa, J. Chil. Chem. Soc. 49, 137 (2004).

10.- A. Urzúa, R. Santander, J. Echeverría, M. C. Rezende, J. Chil. Chem. Soc. 52, $1142(2007)$

11.- A. M. Haddad, M. E. Pereira, Biomed. Chrom. 12, 34 (1998)

12.- L. K. Duffin, D. J. Henion, Anal. Chem. 63, 1781 (1991)

13.- J. J. Myher, L. Marai, A. Kuksis, J. Lipid Res. 15, 586 (1974)

14.- E. Rodriguez, P. L. Healey, I. Metha, (eds). Biology and Chemistry of Plant Trichomes, Plenum Press, New York, 2004; pp. 187-241.

15.- H. Merxmüller, P. Leins, H. Roessler, Inuleae-systematic review. In: V. H. Heywood, J. B. Harborne, B. L. Turner, (eds). The Biology and Chemistry of the Compositae Vol 1, Academic Press, London, 1977; pp. 577-602.

16.- Anderberg, A.,. Tribe Inuleae. In: Bremer, K. (eds). Asteraceae: Cladistics and Classification, Timber Press, Portland, Oregon, 1994; pp. 145-177.

17.- M. O. Dillon, A. Sagástegui, Arnaldoa, 1,5 (1991) 